\title{
Gastric Metastasis of Malignant Melanoma: Report of a Case and Review of Available Literature
}

\author{
Nader El-Sourani Achim Troja Hans-Rudolph Raab Dalibor Antolovic \\ Department of General and Visceral Surgery, University Clinic Oldenburg, Oldenburg, Germany
}

\section{Keywords \\ Malignant melanoma - Gastric mucosa · \\ Melanoma of the stomach $\cdot$ Metastasis}

\section{Summary}

Background: Malignant melanoma is a tumor with common lymphogenic or hematogenic metastasis. Metastasis to the gastric mucosa is uncommon. Case Report: We present the case of a 43-year-old female patient with metastases of a malignant melanoma to the lesser curvature of the stomach. The primary malignant melanoma of the right breast was resected 2 years previously. Conclusion: Metastases to the gastric mucosa are rarely seen. Esophagogastroduodenoscopy should be performed in symptomatic patients to rule out metastatic disease. When $\mathrm{R} 0$ resection can be achieved, it should be undertaken in order to increase the overall prognosis of the patient.

\section{Introduction}

Melanoma is a malignant tumor of melanocytes and predominantly occurs in the skin. It accounts for $90 \%$ of all deaths related to skin cancer [1]. Due to its aggressive behavior and high rate of metastases, the overall prognosis is poor. Two thirds of all primary metastases are confined to the regional lymphatic system. The American Joint Committee on Cancer (AJCC) classifies the melanoma staging system into three groups [2]. The overall 10 -year survival rate is $75-80 \%$. In the presence of distant metastases, the median survival rate is 6-9 months. Prolonged survival time reported in a few patients with gastrointestinal metastases is associated with ag-

\author{
Schlüsselwörter \\ Malignes Melanom - Magenschleimhaut . \\ Melanom des Magens - Metastase
}

\section{Zusammenfassung}

Hintergrund: Das maligne Melanom ist ein bösartiger Tumor mit häufiger lymphogener oder hämatogener Metastasierung. Eine Metastasierung in den Magen ist ungewöhnlich. Fallbericht: Wir berichten im Folgenden über eine 43-jährige Patientin mit einer Metastase des vorbekannten malignen Melanoms im Magenkorpus kleinkurvaturseitig. Das primäre maligne Melanom der rechten Brust wurde 2 Jahre zuvor reseziert. Schlussfolgerung: Eine Metastasierung des Magens ist ungewöhnlich. Zur Komplettierung des Stagings und zum Ausschluss von Fernmetastasen sollte bei symptomatischen Patienten eine Ösophagogastroduodenoskopie durchgeführt werden. Bei einer möglichen Ro-Situation sollten Fernmetastasen aufgrund einer per se günstigeren Prognose des Patienten reseziert werden.

gressive surgical treatment in combination with chemotherapy. Metastases to the gastrointestinal tract are common. Common sites include the small bowel, large bowel, and anorectum. Metastases to the stomach are rare [3]. We present the case of a 43-year-old female patient with a malignant melanoma of the stomach.

\section{Case Report}

We present the case of a 43-year-old female patient with a known malignant skin melanoma of the right breast. The melanoma was excised 2 years previously. The postoperative tumor stadium was pT2b N1b M0. The sentinel lymph node biopsy of the right axilla was positive, leading to

\section{KARGER}

Fax +497614520714

Information@Karger.com

www.karger.com (c) 2014 S. Karger GmbH, Freiburg

1662-6664/14/0304-0273\$39.50/0

Accessible online at:

www.karger.com/vim
Nader El-Sourani

Universitätsklinik für Allgemein- und Viszeralchirurgie Klinikum Oldenburg

Rahel-Straus-Straße 10, 26133 Oldenburg, Germany

nader@elsourani.com 
Fig. 1. Mass seen during EGD (a) and after surgical resection (b).
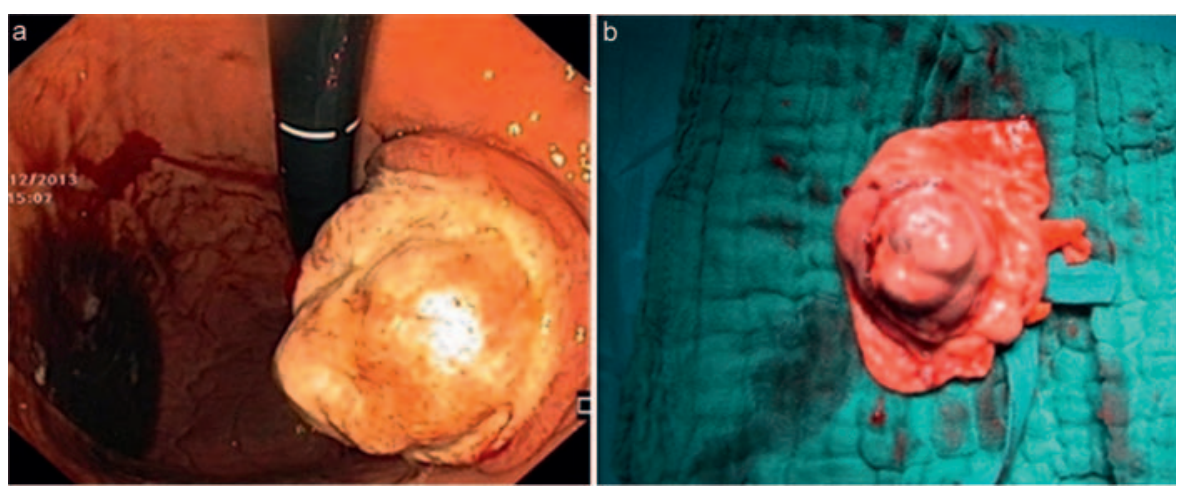

a lymphadenectomy of the right side. Additional skin metastases were not seen. To rule out any distant metastases, computed tomography (CT) and magnetic resonance imaging (MRI) were performed. No distant metastases were seen, specifically no lung and brain metastases. A full clinical examination of the patient was done to rule out the presence of other skin lesions.

Our patient presented with melena and anemia. In order to rule out an underlying cause as well as metastases of the mucosa, we performed an upper and lower endoscopy. The esophagogastroduodenoscopy (EGD) showed an approximately $5 \mathrm{~cm}$ large mass with deep central ulceration at the lesser curvature of the body of the stomach (fig. 1). The rest of the stomach, the esophagus, and the first part of the duodenum were normal. The histological examination of the biopsies confirmed the diagnosis of a malignant melanoma. CT and MRI ruled out further metastases. In the presence of a solitary metastasis of the stomach, a surgical approach was indicated.

Intraoperatively, the mass was seen at the lesser curvature of the body of the stomach. After exploring the abdomen for metastatic disease (e.g. peritoneum, liver), we performed an atypical resection of the stomach as a sleeve gastrectomy (fig. 2) with a complete locoregional lymphadenectomy at the lesser curvature. The histological examination of the excised mass described a metastasis of the primarily known malignant melanoma with three tumor-infiltrated and five tumor-free lymph nodes. The surgical margins were free. The postoperative period was uneventful. The patient was discharged in good general health and without any further symptoms.

\section{Discussion}

Melanoma is a malignant tumor of melanocytes and predominantly occurs in the skin. It is highly aggressive with an early tendency to metastasize. Metastases to the gastrointestinal tract are common, with common sites including the small bowel (50\%), large bowel (31\%), and anorectum (25\%). Metastases to the lesser curvature of the stomach are rare [4]. Concerning the anatomical site of gastric metastases, the majority of these are reported to occur in the body and the fundus of the stomach, i.e. most often at the greater curvature, with lesions of the lesser curvature being very uncommon [5]. In our patient, the lesion was located in the lesser curvature of the body of the stomach (fig. 1).

$\mathrm{CT}$ and MRI ruled out any presence of distant metastases. Clinical examination showed no evidence of further lesions. In the presence of a symptomatic solitary metastasis of the

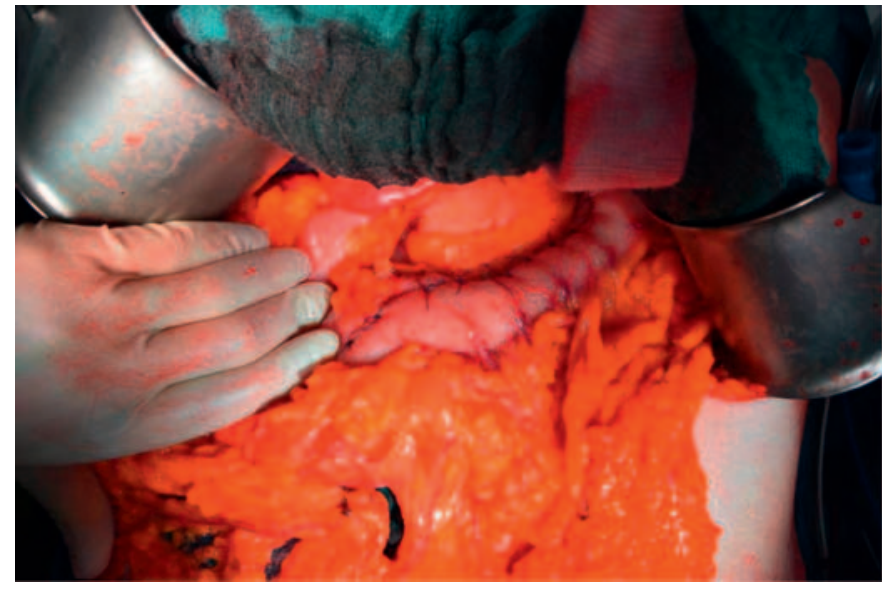

Fig. 2. Sleeve gastrectomy after atypical resection.

stomach, a surgical approach was indicated to warrant an R0 resection and to achieve symptom control. This is in accordance with the available published literature [6]. It was shown that an R0 status could improve the long-term survival rate and in some cases led to a disease-free life [7]. A resection of symptomatic metastases is always indicated in order to improve the quality of life.

The malignant melanoma of the stomach is mostly asymptomatic and explains why it largely eludes detection. Symptoms include nausea, vomiting, gastrointestinal bleeding, weight loss, and occasionally an acute perforation. Our patient presented with melena and anemia. The EGD showed a deep, central ulcer at the lesser curvature of the body of the stomach.

The endoscopic classification of gastric metastases comprises three main morphological types [8]. Firstly, there are melanotic nodules, often ulcerated at the tip. Secondly, there are submucosal tumor masses which are elevated and ulcerated at the apex. The last morphological type is a mass lesion with varying incidence of necrosis and melanosis.

In the available published literature, gastric invasion was most often associated with the invasion of other organs, which is contrary to our case. Therefore, every case of metastatic malignant melanoma with clinical upper gastrointestinal 
symptoms such as melena should undergo endoscopic examination for gastrointestinal metastases.

\section{Conclusion}

The malignant melanoma has an early tendency to metastasize. Although metastases to the stomach are rare, an upper endoscopy should be performed to rule out metastatic disease. A primary melanoma of the stomach is extremely rare and can only be diagnosed in the absence of other lesions. In the setting where an $\mathrm{R} 0$ resection can be achieved, distant metastases should be resected in order to increase the patient's overall prognosis. Patients should be treated within an effective, multimodal network.

\section{Disclosure Statement}

No conflict of interest.

\section{References}

1 Leitlinie Malignes Melanom: Diagnostik, Therapie und Nachsorge. www.awmf.org/leitlinien/detail/ll/ 032-024OL.html.

2 Balch CM, Buzaid AC, Soong SJ, et al: Final version of the American Joint Committee on Cance staging system for cutaneous melanoma. J Clin Oncol 2001;19:3635-3648.

3 Blecker D, Abraham S, Furth EE, et al: Melanoma in the gastrointestinal tract. Am J Gastroenterol 1999;94:3427-3433.
4 Goral V, Ucmak F, Yildirim S, et al: Malignant melanoma of the stomach presenting in a woman: a case report. J Med Case Rep 2011;5:94

5 Booth JB: Malignant melanoma of the stomach: report of a case presenting as an acute perforation and review of the literature. Br J Surg 1965;52: 262-270.

6 Brega K, Robinson WA, Winston K, Wittenberg W: Surgical treatment of brain metastases in malignant melanoma. Cancer 1990;66:2105-2110.
7 Leo F, Cagini L, Rocmans P, Cappello M, van Geel AN, Maggi G, Goldstraw P, Pastorino U: Lung metastases from melanoma: when is surgical treatment warranted? Br J Cancer 2000;83:569-572.

8 Iconomou TG, Tsoutsos D, Frangia K, et al: Malignant melanoma of the stomach presenting with an unknown primary lesions. Eur J Plast Surg 2003; 26:153-155. 